\title{
The effect of the Cornwall and Isles of Scilly helicopter ambulance unit on the ambulance services' ability to deliver acutely traumatized patients to hospital
}

\author{
A. ROUSE MFPHM \\ Cornwall and Isles of Scilly Health Authority, Department of Public Health Medicine, \\ Truro, England
}

\section{SUMMARY}

Objective: to determine whether the use of a helicopter ambulance unit enabled an ambulance service to deliver acutely traumatized patients to hospital more quickly. Design: retrospectively collected ambulance service and hospital records data analysed longitudinally. Settings: The ambulance service and the major casualty department in Cornwall. Intervention: the provision of a helicopter ambulance unit to a county ambulance service. Subjects: patients with compound lower limb fractures carried as emergencies by an ambulance service. Principle outcome measure: ambulance 'mission times'. Results: the ambulance services' ability to deliver emergency patients to hospital more quickly when the helicopter unit was available was not demonstrated. In some instances availability of the helicopter unit probably delayed the timely delivery of emergency patients to the casualty department. Conclusion: until a more effective helicopter deployment strategy is in operation it is unlikely that mission time savings will occur.

\section{INTRODUCTION}

Cornwall has a population of over 450000 and covers over 1400 square miles. Large areas, particularly in the east of the county, are thinly populated. Provision of ambulance services is complicated by this scatter of population. Some residents live over 35 miles from an acute care hospital. Since April 1987 the Cornwall

Correspondence: A. Rouse, Cornwall and Isles of Scilly Health Authority, Senior Registrar, Department of Public Health Medicine, Truro IRI INR, England. 
and Isles of Scilly Ambulance Service has been augmented by the provision of a helicopter fitted out as an ambulance. This paper reports a 'management study' (Fletcher et al., 1988) which sought to evaluate whether the ambulance service was able to deliver patients to hospital more quickly when the helicopter ambulance was operating.

\section{Study details}

Principle outcome measure - mission time.

'Mission time' is the time difference between the ambulance service being notified of an emergency and delivering the patient to the appropriate hospital. The three separate components which comprise mission time; arrival at scene time (AAST), on-scene time, and travel time to hospital are shown in Fig. 1.

Study group

Patients with compound fractures of the lower limb who attended Royal Cornwall Hospital City Casualty Department between lst April, 1987 and 30th April, 1989

\section{METHODS}

Casualty records were examined and 83 cases of compound lower limb fractures brought in by the ambulance service identified. These 83 cases were divided into four mutually exclusive groups depending upon the time of origin of the emergency call to the ambulance service and whether the helicopter unit was operating (Fig. 2). During the study period the helicopter unit was operational for 8 daylight $h 5$ days a week. Patients carried when the helicopter augmented ambulance service was operating (Groups 1 \& 2) was compared with patients carried when the basic ambulance service was operating (Group 3).

\section{Outcome measures}

The only absolute measure for evaluating emergency response care provided by an ambulance service is a lessening of morbidity and mortality. It is these

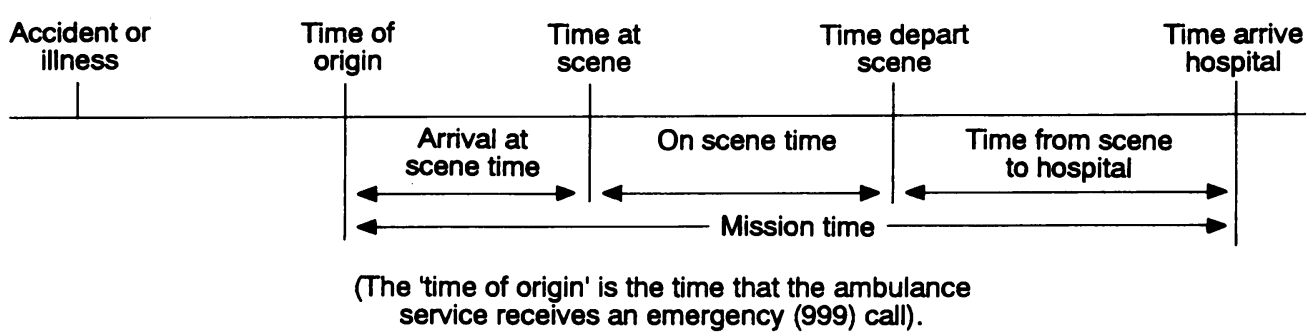

Fig. 1. Diagrammatic representation of health services response to traumatized patient if ambulance service is involved. 


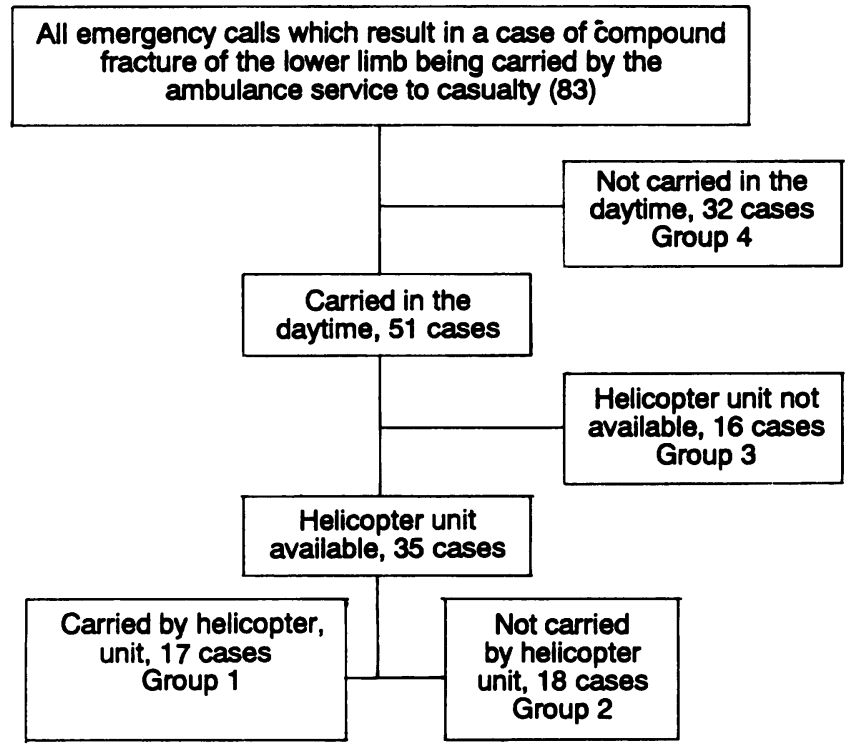

Fig. 2. Formation of study groups.

which should be studied when the impact of a helicopter unit is being examined. Preliminary studies showed that serious injury is an infrequent event in Cornwall and that even if the beneficial effect of a helicopter unit is to reduce mortality by half (from 5 to $2.5 \%$ ) for study groups of patients, it would take years to demonstrate convincingly such an improvement. Therefore, it was decided to use the interim process measure of mission time as the primary proxy measure of outcome. The arrival at scene time was used as a secondary proxy measure. The use of proxy/ surrogate outcome measures is a commonly employed epidemiological technique (Anon, 1990). Justification for the use of these measures is that a major factor determining the outcome of the critically ill patient is the 'therapy free interval'. The therapy free interval may end when: (1) an ambulance crew arrive at the scene of an incident and gives useful therapy. Thus the minimum therapy free interval is the 'arrival at scene time'. However, although there may be good theoretical reasons for believing that patient care is improved by treatments given by ambulancemen, this has not been convincingly demonstrated for trauma victims (Anderson et al., 1987); and (2) a patient is delivered to a major casualty department. In such circumstances the therapy free interval will be the 'mission time' or longer. Definitive interventions can also be given once the patient is in hospital. Numerous authorities are agreed upon the importance of reducing this time to a minimum (Redmond, 1984, Mackenzie et al., 1988). For patients who have suffered serious trauma the most advantageous thing an ambulance service may do is 'scoop and run', the patient to a trauma centre (Redmond, 1984). 


\section{RESULTS}

\section{Mission times}

The basic ambulance service delivered $43 \%$ of cases to hospital within $1 \mathrm{~h}$ (Fig. 3). The helicopter augmented service delivered only $31 \%$ of cases to hospital in $1 \mathrm{~h}$.

The $95 \%$ confidence interval for this decreased performance of $12 \%$ is between $-41 \%$ and $+17 \%$ (Daniel, 1987) These findings are also compatible with a $90 \%$ chance that the helicopter unit might, over a longer period of, time, confer a benefit as great as $20 \%$ (from $43 \%$ to $52 \%$ ) at $1 \mathrm{~h}$ (Beta error) (Colton, 1974).

These are not the expected findings. It would appear that the longer mission times associated with operation of the helicopter unit augmented ambulance service arose as a direct consequence of its use. When the helicopter augmented ambulance service was operating the helicopter itself was used in $48 \%(17 / 35)$ of these missions. Figure 4 shows the utilization pattern of the helicopter in the 17 missions in which it was involved. Figure 4a shows that in 14 of these 17 missions a land ambulance arrived at the scene of the accident first. This ambulance then requested the helicopter. Figure $4 \mathrm{~b}$ shows that in two missions the helicopter was the only ambulance deployed. In one mission the helicopter unit was the first vehicle on-scene. The helicopter unit then requested a land ambulance to transport the patient $(4 \mathrm{c})$.

Arrival at scene times (AAST).

The primary deployment of a land ambulance prior to use of the helicopter unito probably explains the similar AAST $(9$ and $10 \mathrm{~min}$ ) in each study group noted in Table 1.

\section{On-scene times}

On-scene times were longer when the helicopter assisted ambulance service was available (Table 2). The increased mean on-scene time of $8.6 \mathrm{~min}$ is statistically significant at the 0.05 level of probability (1 tailed test) (Gardner \& Altman, 1989).

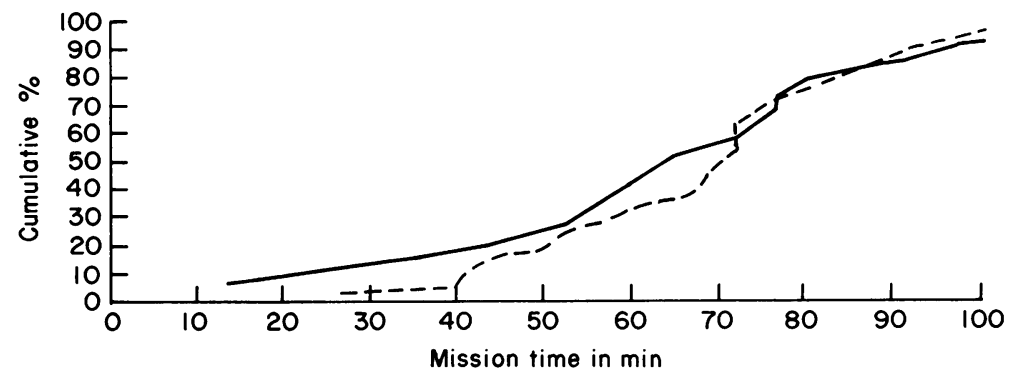

Fig. 3. Cumulative frequency distribution of mission times for the helicopter unit augmented and basic land ambulance service. - - - land ambulance service augmented by air ambulance; unaugmented (basic) ambulance service operating. 
14 Missions

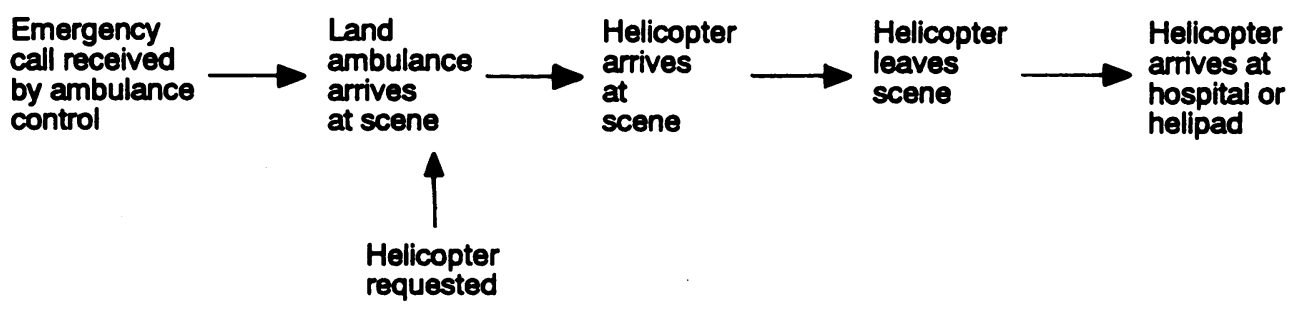

2 Missions

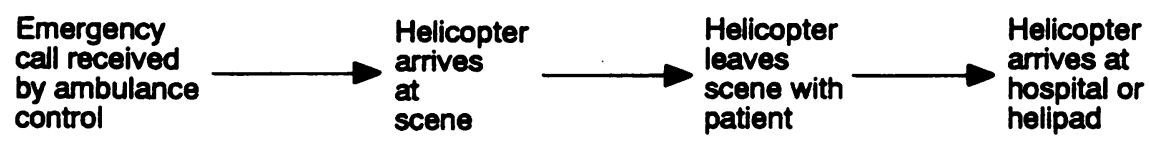

1 Mission

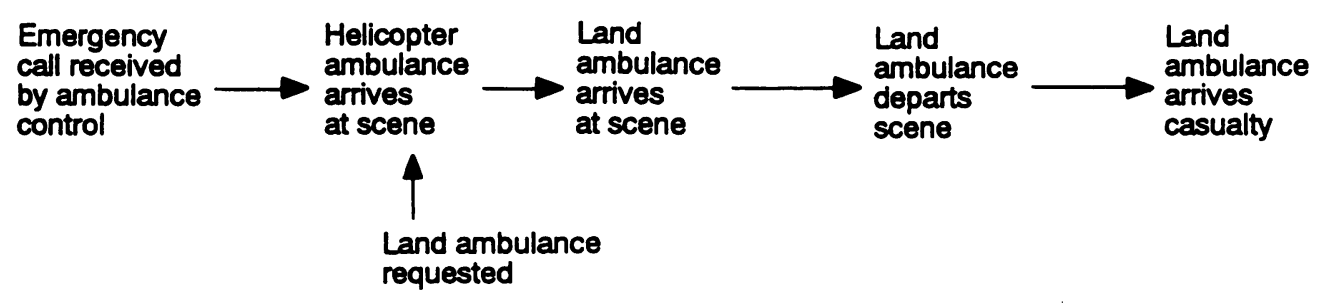

Fig. 4. Sequence of deployment of a helicopter unit.

Table 1. Arrival at scene times.

\begin{tabular}{lcc}
\hline Carried by & $\begin{array}{c}\text { Median completion } \\
\text { AAST }\end{array}$ & $\begin{array}{c}80 \text { percentile } \\
\text { completion AAST }\end{array}$ \\
\hline $\begin{array}{l}\text { Helicopter augmented } \\
\text { Service - Groups 1 \& 2. }\end{array}$ & 9 & 13 \\
$\begin{array}{l}\text { Basic ambulance } \\
\text { service - Group 3. }\end{array}$ & 10 & 13 \\
\hline
\end{tabular}

Longer on-scene times probably result from the fact that the helicopter unit was often used as a secondary response vehicle (Fig. 4a). Whilst the helicopter was being activated (data on file show average activation time of the helicopter is $3 \mathrm{~min}$ ) and flying out to the scene the on-scene time was lengthening and probably accounts for the longer on-scene times noted in Table 2. 
Table 2. On-scene times in minutes.

\begin{tabular}{lccc}
\hline Patients carried by & $\begin{array}{c}\text { Mean time on- } \\
\text { scene }\end{array}$ & $\begin{array}{c}\text { Standard } \\
\text { deviation }\end{array}$ & $\begin{array}{c}\text { Median time } \\
\text { on-scene }\end{array}$ \\
\hline $\begin{array}{l}\text { Basic ambulance } \\
\text { service }\end{array}$ & 27.2 & 14.5 & 24 \\
$\begin{array}{l}\text { Helicopter augmented } \\
\text { ambulance service }\end{array}$ & 35.8 & 17.3 & 37 \\
\hline
\end{tabular}

Times from scene to hospital

Since the helicopter unit is a high speed vehicle and was used in $48 \%$ of missions one might expect transit times from the scene to the hospital to be shorter when the helicopter augmented ambulance service was available. This is, indeed, the case as Table 3 shows.

However, time savings are not as great as they might be because in 12 of the 17 helicopter missions, the helicopter did not land at the major casualty department but at a helipad 2 miles away. From the helipad the patient was transferred by land ambulance and brought to the A\&E Department. Records are kept of the times of these journeys so it is possible to 'modify' this time and plot the gain that would accrue if the helipad was adjacent to the casualty department. Records show that between 4 and $30 \mathrm{~min}$ could be saved if A\&E were situated next to the helipad.

It must be noted with reference to Fig. 5 that even with these shortened times the time saved on the journey back from the scene of an accident only just compensates for the extra time spent on scene when the helicopter unit is used.

\section{DISCUSSION}

\section{Effect of an helicopter unit on ambulance service performance}

There are several different mechanisms by which availability of a helicopter unit is expected to influence ambulance service performance. The primary expectation is of shorter mission times when the helicopter unit transports patients. However,

Table 3. Times from scene to hospital.

\begin{tabular}{lcc}
\hline & $\begin{array}{c}\text { Median time from } \\
\text { scene to hospital }\end{array}$ & $\begin{array}{c}80 \text { percentile } \\
\text { time from } \\
\text { scene to hospital }\end{array}$ \\
\hline $\begin{array}{l}\text { Carried when helicopter } \\
\text { augmented ambulance } \\
\text { operating. }\end{array}$ & $20 \mathrm{~min}$ & $38 \mathrm{~min}$ \\
$\begin{array}{l}\text { Parients carried when } \\
\text { basic ambulance } \\
\text { service operating. }\end{array}$ & $27 \mathrm{~min}$ & $44 \mathrm{~min}$ \\
\hline
\end{tabular}




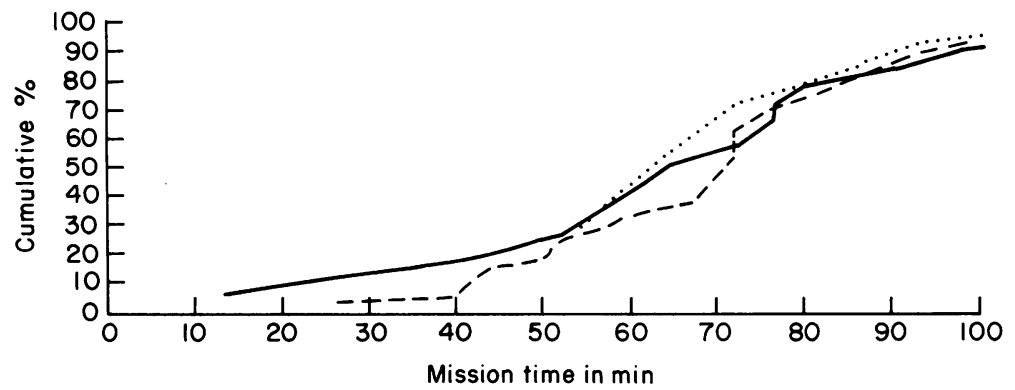

Fig. 5. To show improvement in mission times of a helicopter augmented ambulance service if the helipcid were located adjacent to the A\&E department. - - - , land ambulance service augmented by

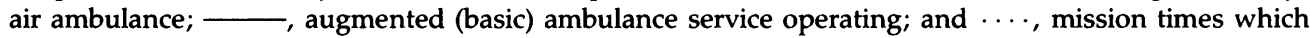
could have been expected if a helipad had been located near A\&E.

extensive review of many medical and ambulance records and discussion with numerous people involved with operation of the helicopter unit found no evidence for this. A secondary expectation is that a helicopter unit could also have an indirect beneficial effect by providing some 'cover' across the county, so allowing a more effective deployment of land ambulances elsewhere. This benefit would also be expressed by improved mission times of the entire ambulance fleet. Interviews with ambulance service workers suggest that this is where the greatest benefits of helicopter unit usage might be found.

\section{Patient and mission characteristics}

Table 4 shows that the two groups of patients seem very similar to each other. It is unlikely, therefore that any patient related factor is responsible for the reduced proportion of patients delivered to hospital within $1 \mathrm{~h}$ or the longer on-scene times, noted when the helicopter augmented service was operating.

\section{AAST and mission times.}

This study shows that availability of a helicopter unit did not lessen the Therapy Free Interval by reducing mission times and delivering patients to hospital more quickly. Nor did it show that a helicopter augmented ambulance service reduced the Therapy Free Interval by shortening AAST times and making treatment available at scene more quickly.

\section{Selection of study groups}

This study was confined to trauma cases because preliminary studies showed that the helicopter was often used for dealing with emergency trauma cases and that this is the aspect of ambulance service work where advocates of the use of helicopter ambulancs, the public and medical personnel, expect to find the benefits of a helicopter unit.

Patients with compound fractures of the lower limb were studied as: (1) they 
Table 4. Patients and missions characteristics of those carried by a helicopter augmented or basic ambulance service.

\begin{tabular}{lcc}
\hline Characteristic & $\begin{array}{c}\text { Helicopter augmented } \\
\text { ambulance service } \\
\text { (Groups 1 \& 2) }\end{array}$ & $\begin{array}{c}\text { Basic ambulance } \\
\text { service } \\
\text { (group 3) }\end{array}$ \\
\hline $\begin{array}{l}\text { No. of patients } \\
\text { M:F }\end{array}$ & $\begin{array}{l}(28 / 4) 4: 1 \\
\text { Median age } \\
\text { male (No.) }\end{array}$ & $\begin{array}{l}16 \\
(12 / 4) 3: 1\end{array}$ \\
$\begin{array}{l}\text { Median age } \\
\text { female (No.) }\end{array}$ & 25 years (28) & 30 years (12) \\
$\begin{array}{l}\text { No. of road } \\
\text { Traffic }\end{array}$ & 69 years (7) & 44 years (4) \\
$\begin{array}{l}\text { Accidents } \\
\text { Median AAST } \\
\text { time }\end{array}$ & $19 / 35(54 \%)$ & $8 / 16(50 \%)$ \\
$\begin{array}{l}\text { Median distance } \\
\text { (road miles) } \\
\text { from Truro A\&E } \\
\text { department }\end{array}$ & 10 min & 9 min \\
$\begin{array}{l}\text { 80\% percentile } \\
\text { (road miles) } \\
\text { distance from } \\
\text { A\&E department }\end{array}$ & 17 miles & \\
$\begin{array}{l}\text { Median time to } \\
\text { operation } \\
\text { min }\end{array}$ & 24 miles & 17 miles \\
\hline
\end{tabular}

comprise a significant portion of all seriously injured patients: (2) they are easy to define retrospectively and; (3) they are relatively common. Since there is a substantial body of surgical opinion that these patients need to be assessed for other injuries and operated upon quickly (Raines \& Richie, 1981), and that early operation for stabilization decreases morbidity, duration of hospitalization and cost (Mackenzie et al., 1988), they serve as a clinically important study group.

\section{Survivor effect - effect of pre-hospital mortality}

Ambulance service records were reviewed and details of ambulance service involvement in all cases of pre-hospital mortality was obtained. There were four such cases none of which arose at a time when the helicopter was or could have been operating. This evidence supports the view that there was no differential prehospital mortality in the two study groups.

\section{An ethical issue}

This study raises the possibility that if rapid delivery of patients to hospital is of prime importance, patient care might deteriorate as a consequence of helicopter unit usage. Deterioration in patient care as a result of providing higher skills 
training to ambulancemen is documented (Redmond, 1984). There is a case to be made that air ambulances should only be introduced under experimental conditions, and provision made for their discontinuation if it appears that patient care is jeopardized.

\section{CONCLUSIONS}

It would appear that until a means can be found of deploying the helicopter unit in a more effective manner, probably by directing it to incidents as the primary and only response vehicle, mission time savings will not occur.

\section{ACKNOWLEDGEMENTS}

Thanks to M. Sheen, N. Sellwood and D. Miles.

\section{REFERENCES}

Anderson I. W. R., Black R. J., Ledingham I. M., Little K., Robertson C. E. \& Urquhart J. D. (1987) Early emergency care study: the potential and benefits of advanced prehospital care. British Medical Journal 294, 228-231.

Anonymous. (1990) Surrogate measures in clinical trials. editorial. The Lancet 335, 261-262.

Colton T. (1974) Statistics in Medicine, pp. 120. Little Brown \& Co., New York.

Daniel D. (1987) Biostatistics: A Foundation For The Health Sciences, PISO. 4th ed. John Wiley \& Sons, London.

Fletcher R., Fletcher S. \& Wagner E. (1988) Clinical Epideniology. Williams \& Wilkins, pp. 145.

Gardner M. J. \& Altman D. G. (1989) Statistics with Confidence. British Medical Journal 21.

Gregg P. J. (1992) Fractures and dislocations - general principles of management. In: C. V. Mann \& R. C. G. Russell (eds) Bailey E Loves Short Practice of Surgery, pp. 283. Chapman \& Hall Medical, London.

Mackenzie R. C., Hoyt D. B. \& Sedivitz M. M. (1988) Complications in trauma management. A. Cushieri, G. R. Giles, \& A. R. Mossa, (eds). Essential Surgical Practice. pp. 268. John Wright, London.

Redmond A. D. (1984) Paramedics in the United Kingdom. British Medical Journal 288, 622-623. 